\title{
Anisotropic behaviour of compacted clayey silt subjected to hydro- mechanical paths
}

\author{
Carlos Buenfil $^{1}$, Enrique Romero ${ }^{2, a}$, Antonio Lloret $^{2}$ and Antonio Gens ${ }^{2}$ \\ ${ }^{1}$ Universidad Autónoma de Campeche and Instituto Tecnológico de Campeche, Mexico \\ ${ }^{2}$ Universitat Politècnica de Catalunya, Spain
}

\begin{abstract}
Compaction induces anisotropy on soil deformational response due to preferential straining associated with the fabrication process. An experimental insight into the stress-strain response of Barcelona clayey silt is provided here. The material was statically compacted at low dry density to induce high collapsibility upon wetting (dry density $1.48 \mathrm{Mg} / \mathrm{m}^{3}$, water content $12 \%$ ). Two types of controlled-suction tests were carried out: a) constant suction radial paths on as-compacted samples following different stress ratios (deviator stress / mean net stress: $q / p^{\prime \prime}$ ), including isotropic and $\mathrm{K}_{0}$ stress paths; and $\mathrm{b}$ ) the same type of radial stress paths but performed after saturation under low confining stress. These paths were intended to define the as-compacted and saturated yield surfaces. The experimental data on as-compacted state is satisfactorily interpreted adopting an anisotropic yield surface with an inclination linked to the compaction under oedometer conditions. Development of shear strain was observed during isotropic loading of the compacted samples. This anisotropy that the soil exhibits at the end of the compaction vanishes after collapse by saturation and as plastic volumetric straining develops.
\end{abstract}

\section{Introduction}

The effect of the anisotropy derived from the compaction process is one aspect of the behaviour of unsaturated compacted that has received relatively less attention. Despite the significance in practical applications, this initial anisotropy and its evolution along general stress paths have not been usually taken into account in the constitutive formulations proposed to model the behaviour of compacted soils. This article presents the results of a study on the deformational behaviour of a clayey silt, which was compacted under oedometer conditions and was subjected to different stress paths and suction changes.

Compaction can induce anisotropy on soil response due to important and preferential straining associated with the fabrication process, particularly when using static compaction under oedometer conditions. This anisotropic deformation pattern induces a transversally isotropic structure, resulting in larger stiffness and strength in the axial direction.

There are a number of experimental studies on unsaturated compacted soils [1-5]. Cui and Delage [1] were probably the first authors to present results from anisotropic loading tests on a compacted silt showing yield surfaces at constant suction, which were inclined with the major axis coinciding with the $K_{0}$ (at rest earth pressure coefficient) line. This behaviour is similar to that observed in natural saturated soils. Romero and Jommi [5] showed and modelled the distortional effects that were expected to accompany volumetric strains of onedimensionally compacted soils during wetting processes under isotropic stress conditions. The changes in the direction of plastic strain increment vectors observed experimentally by these authors upon wetting contributed to a better definition of the anisotropy evolution.

\section{Characterization of the tested soil}

Laboratory tests were performed on a low plasticity clayey silt from Barcelona. It has a liquid limit of $w_{L}=28 \%$, a plastic limit of $w_{P}=19 \%$, a clay-size fraction $\leq$ $2 \mu \mathrm{m}$ of $19 \%$ and a silty fraction of $47 \%$. Density of solids is $2.67 \mathrm{Mg} / \mathrm{m}^{3}$.

Triaxial samples (38 mm diameter and $76 \mathrm{~mm}$ high) at a prescribed water content of $12.0 \%$ were prepared at a dry density of $\rho_{d}=1.48 \mathrm{Mg} / \mathrm{m}^{3}$ (degree of saturation of $S_{r}=40 \%$ ), by one-dimensional static compaction. Maximum fabrication vertical net stress was $0.27 \mathrm{MPa}$. Lateral stresses were measured by an active lateral stress system, resulting in a lateral stress coefficient at rest of $K_{0}=0.48$ [6]. Suction after compaction, $s=270 \mathrm{kPa}$, was measured using a high-range tensiometer. A relatively low dry density was selected with the aim of inducing an open structure, which was susceptible to undergo important void ratio changes on loading and in turn to induce important changes of the hydro-mechanical properties of the soil.

Retention curves of the clayey silt were obtained using a controlled-suction oedometer cell. Air entry

\footnotetext{
a Corresponding author: enrique.romero-morales@upc.edu
} 
pressure values ranged between $8 \mathrm{kPa}$ and $20 \mathrm{kPa}$ for dry densities of 1.48 and $1.70 \mathrm{Mg} / \mathrm{m}^{3}$, respectively $[6,7]$.

\section{Experimental program}

\subsection{Controlled-suction equipment}

Controlled-suction tests were performed using an automatic triaxial cell $[5,6]$. The deformation response was monitored with local axial (miniature LVDTs attached to the membrane) and radial (electro-optical laser system mounted on two diametrically opposite sides) transducers.

Suction was applied simultaneously via axis translation technique on both ends of the sample, maintaining a constant air pressure and modifying the water pressure. Both top and bottom platens presented a combination of two porous discs: a peripheral annular coarse one connected to the air system and an internal disc with a high air-entry value ceramic (1.5 $\mathrm{MPa})$ connected to the water system.

Two stepper motors operating air pressure regulators were used to continuously control the deviator and confining stresses. The stepper motors and the measurements of 14 transducers were managed by an automatic data acquisition and control system that allowed applying net stress and suction paths, as well as performing strain controlled tests [6].

Tests on saturated specimens were conducted in a conventional automatic triaxial apparatus.

\subsection{Stress paths followed}

Various types of tests were carried out to provide results to study different aspects of soil behaviour minimising the testing time.

Equalisation stages to bring the as-compacted suction (A) to the different target suctions (B) are show in Figure 1. Equalisation was assumed to be achieved once water flow was inducing water content rates lower than $0.04 \%$ /day [5]. All the equalisation stages were performed under a constant mean net stress $p "=(p$ $\left.u_{a}\right)=23 \mathrm{kPa}$ and a deviator stress $q=10 \mathrm{kPa}$.

Constant suction drained compression tests following different stress ratios, $\eta=q / p$ ”, including isotropic $(\eta=0)$ and $K_{0}(\eta=0.75)$ stress paths, were performed. These paths were intended to define the as-compacted yield surfaces, as well as the direction of the plastic strain vectors (paths B-C in Figure 1). The increase of mean net stress was applied at a stress rate of $1.8 \mathrm{kPa} / \mathrm{hr}$, which was assumed adequate to avoid suction changes.

Other types of tests were performed following similar stress paths but after saturating the specimens under low confining stress $(9 \mathrm{kPa}$ for test SI1 and $21 \mathrm{kPa}$ for the remaining tests). The stress paths followed under saturated conditions are indicated in Figure 2.

\section{Results}

\subsection{As-compacted behaviour}

Figure 3 a shows the evolution of void ratio and water ratio (water volume to solid volume: $e_{w}=\rho_{s} w / \rho_{w}$ ) undergone by the soil during the different isotropic compression paths at constant suction $(s=10,100$, $600 \mathrm{kPa}$ and saturated state). It can be observed that the evolution of void ratio displays clear pre- and post-yield domains. Yield stresses increase at higher suctions in accordance with the elastoplastic model of [9]. The postyield compressibility in the figure reduces at higher suctions, also in accordance with the model. For the different tests, the compressibility in the elastic domain, $\kappa(s)$, does not exhibit significant changes with suction. In contrast to the test under saturated conditions, very small changes of water ratio were observed during isotropic compression for suctions of 10,100 and $600 \mathrm{kPa}$. The initial position of the loading-collapse yield locus (LC curve in [9]) that corresponds to the as-compacted state is shown in Figure $3 b$.

Figure 4 shows the evolution of the shear $\varepsilon_{s}$ and volumetric $\varepsilon_{v}$ strains, as well as the ratio between increments in shear strain and volumetric strain $\delta \varepsilon_{s} / \delta \varepsilon_{v}$ of the different samples during the continuous isotropic loading paths under constant suction. These isotropic compression paths were initiated on samples that showed no significant volume changes and remained within the elastic region during the initial suction equalisation stage, and therefore keep a fabric close to what they had at the final state of compaction but at different suctions and water contents.

The evolution of $\delta \varepsilon_{s} / \delta \varepsilon_{v}$ with $\left(p-u_{a}\right)$, developed during isotropic compression, can be used to characterise the degree of anisotropy of the compacted soil. The results plotted in Figure 4 suggest a behaviour closer to the isotropic one when suction decreases. Observed values of $\delta \varepsilon_{s} / \delta \varepsilon_{v}$ at yielding states show a consistent pattern of response with suction $\left(\delta \varepsilon_{s} / \delta \varepsilon_{v}\right.$ of -0.082 for $s=0 \mathrm{kPa}$, 0.114 for $s=10 \mathrm{kPa}$, and -0.206 and -0.214 for $s=100 \mathrm{kPa}$ and $s=600 \mathrm{kPa}$ ), suggesting a slightly greater transverse anisotropy when the soil state is closer to the initial compacted condition $(s=270 \mathrm{kPa})$.

Strain ratio $\delta \varepsilon_{s} / \delta \varepsilon_{v}$ decreases when $\left(p-u_{a}\right)$ increases, and it converges to very small values at the end of the isotropic loading path ( -0.004 and -0.076 for suctions $s=0$ and $s=10 \mathrm{kPa}$, respectively), suggesting that the soil reaches nearly isotropic deformational response as plastic volumetric strain accumulates. A test performed $s=100 \mathrm{kPa}$ fails to stabilise, ending with a strain ratio of about -0.12 . This pattern of behaviour can be explained using the concepts of elasto-plasticity in soils with transverse anisotropy (e.g. $[5,10]$ ), where an isotropic stress increase induces the expansion and rotation of the yield surface towards a more isotropic orientation. 


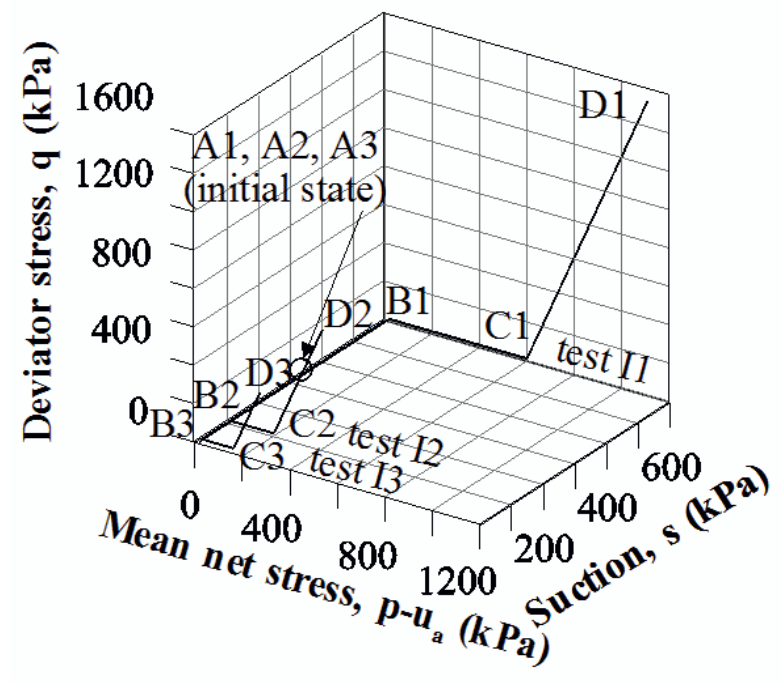

a)

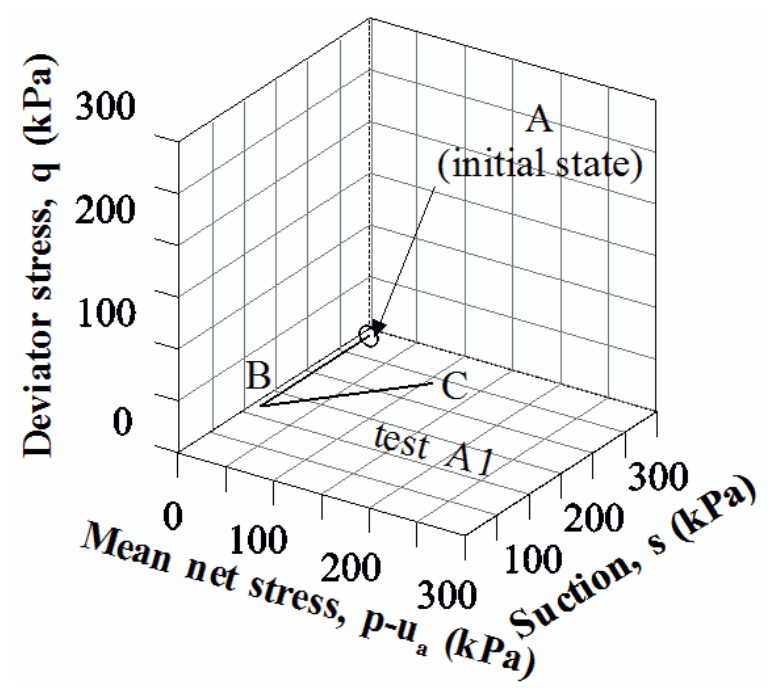

b)

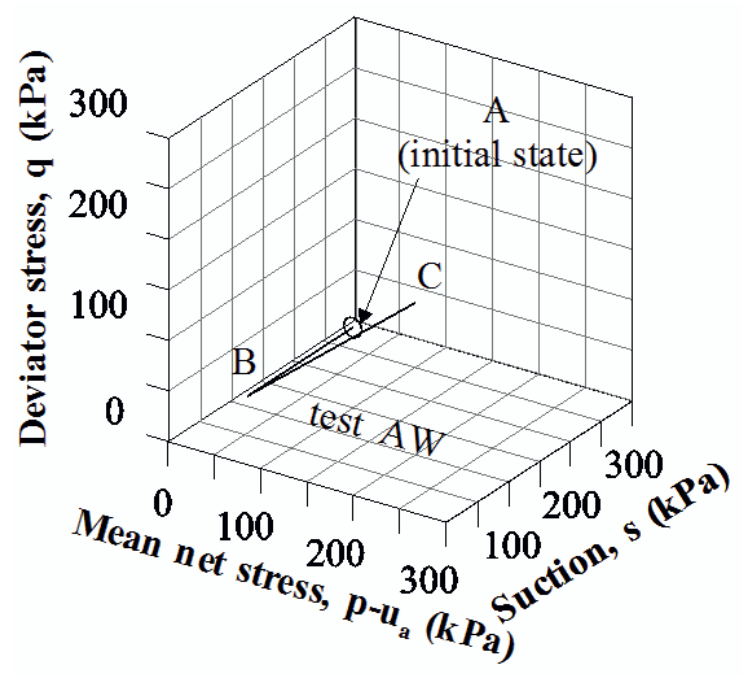

c)

Figure 1. Stress paths in $\left(p-u_{a}\right)-s-q$ space: a) anisotropic $\eta=$ constant loading after initial isotropic compression at constant suction (I1, $s=600 \mathrm{kPa}$; I2, $s=100 \mathrm{kPa}$ and I3, $s=10$ $\mathrm{kPa})$; b) test A1, anisotropic loading $(\eta=0.38)$ at $s=100 \mathrm{kPa}$; $)$ test AW, anisotropic loading $(\eta=0.75)$ at $s=100 \mathrm{kPa}$.

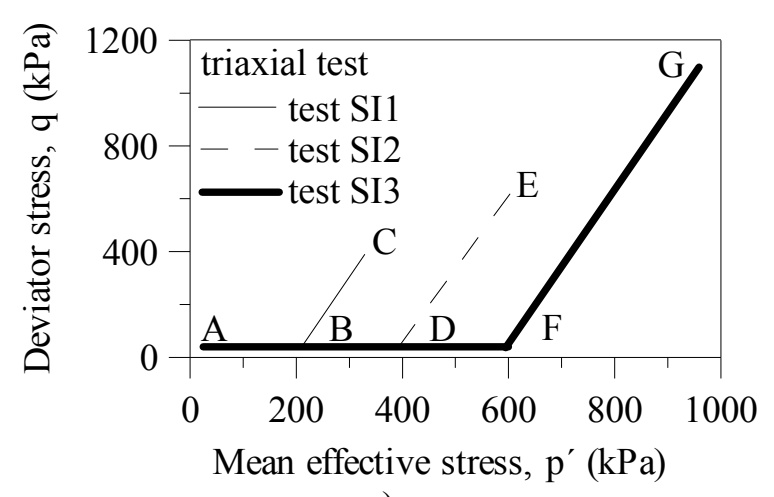

a)

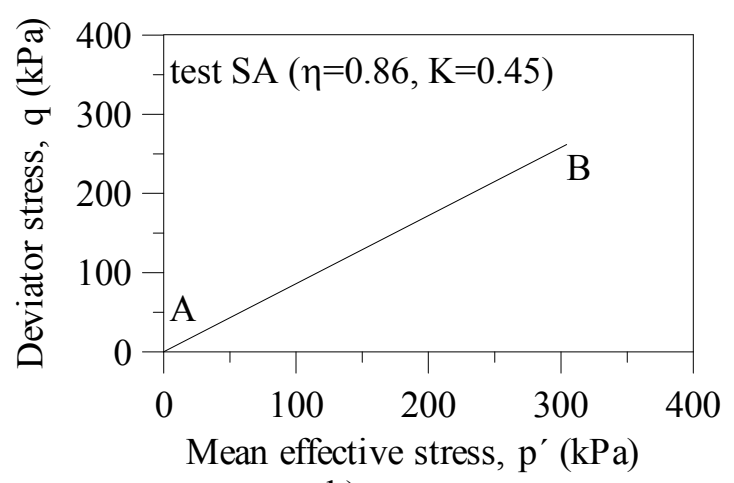

b)

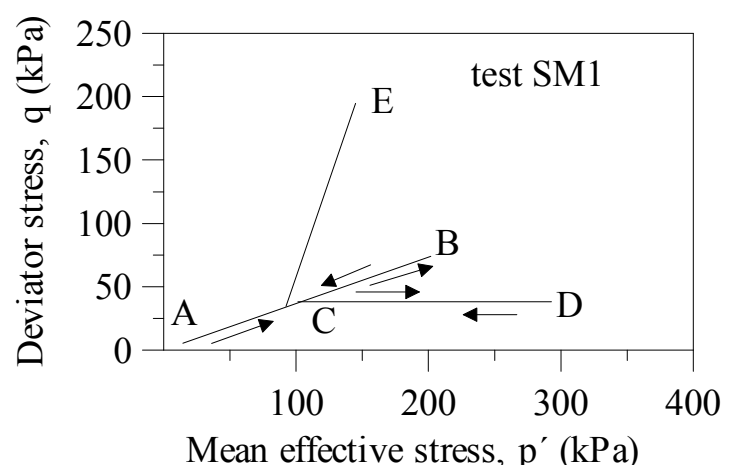

c)

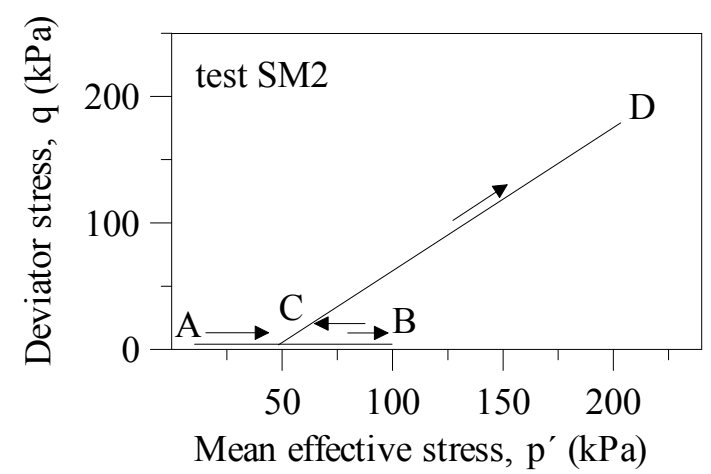

d)

Figure 2. Stress paths in saturated tests. a) SI1, SI2 and SI3 conventional $\mathrm{CD}$ triaxial tests $\left(\Delta q / \Delta p^{\prime}=3\right) ;$ b) test $\mathrm{SA}$, anisotropic loading $(\eta=0.86)$; c) test SM1, anisotropic loading A-B $(\eta=0.36)$, unloading $\mathrm{B}-\mathrm{C}(\eta=0.36)$, isotropic loadingunloading (C-D-C) and conventional loading $\left(\Delta q / \Delta p^{\prime}=3\right)$; $\left.\mathrm{d}\right)$ test SM2, isotropic loading-unloading (A-B-C) and anisotropic loading $(\eta=0.86)$. 


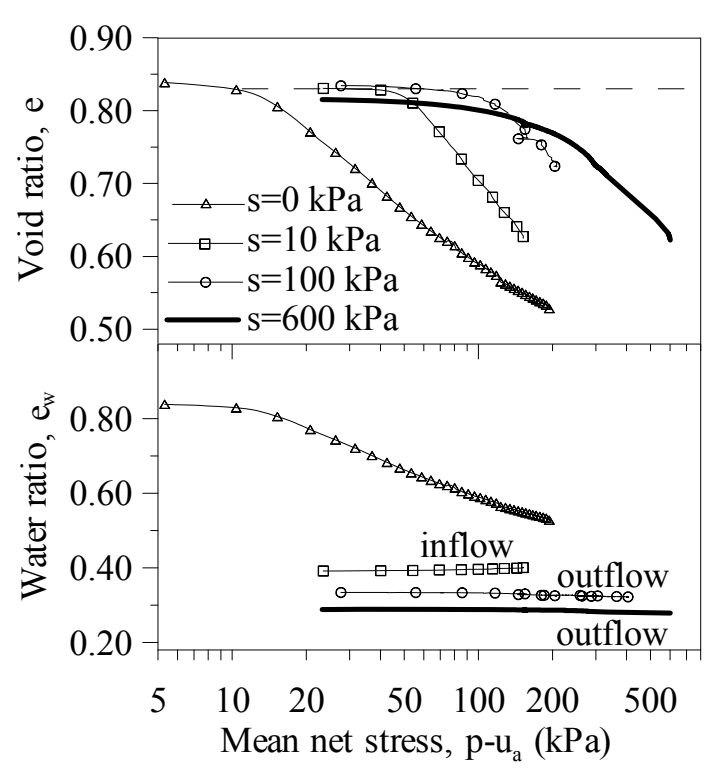

a)

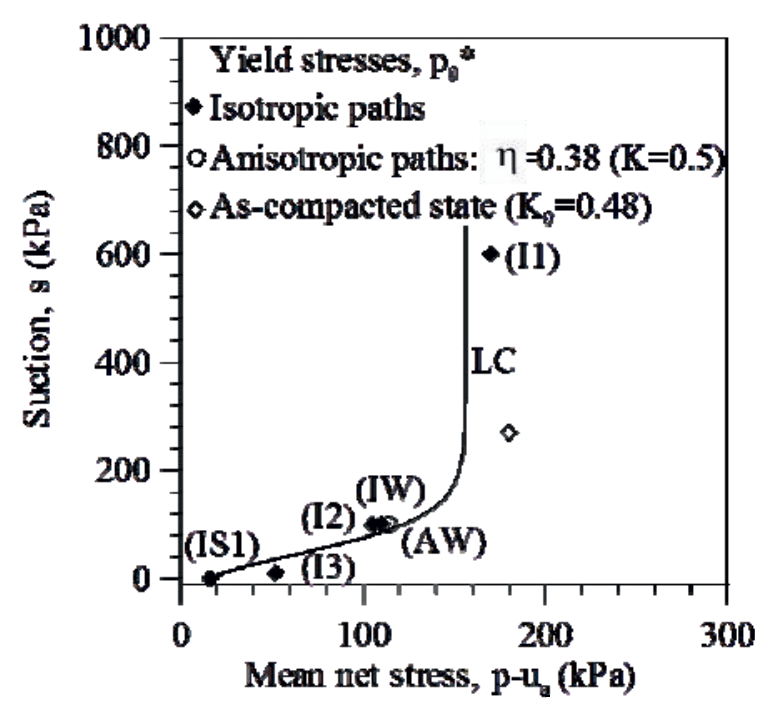

b)

Figure 3. a) Changes in void ratio and water ratio during isotropic compression paths; b) yield stresses and loadingcollapse LC yield curve for as-compacted state.

Figure 5 shows results from anisotropic (A1 and AW) and isotropic (I2) compression tests under a constant suction of $100 \mathrm{kPa}$. As expected, increasing the ratio $\eta$, increases the axial strain and thus increases the shear strains $\varepsilon_{s}$, which change from negative values at $\eta=0$ to positive values at $\eta=0.75$. In the compression test at $\eta=0.38$, the observed shear strains are close to 0 and $\delta \varepsilon_{s} / \delta \varepsilon_{v}$ stabilise at values close to zero when the yield stress is reached. In the compression path at $\eta=0.75$ (close to $K_{0}$ condition) radial strains are lower than the axial ones, with $\delta \varepsilon_{s} / \delta \varepsilon_{v}$ around 0.5 at yield stress (close to the condition of $\varepsilon_{r}=0$ and $\delta \varepsilon_{s} / \delta \varepsilon_{v}=2 / 3$, which are characteristic of oedometer conditions). During the isotropic compression paths the radial strains are greater than the axial ones with $\delta \varepsilon_{s} / \delta \varepsilon_{v}=-0.21$ at the yield point.

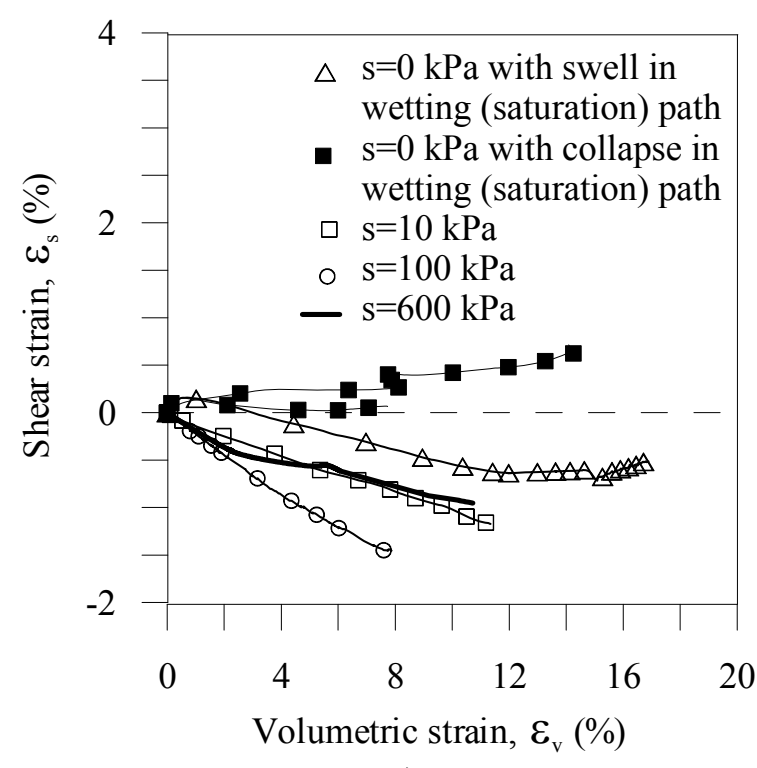

a)

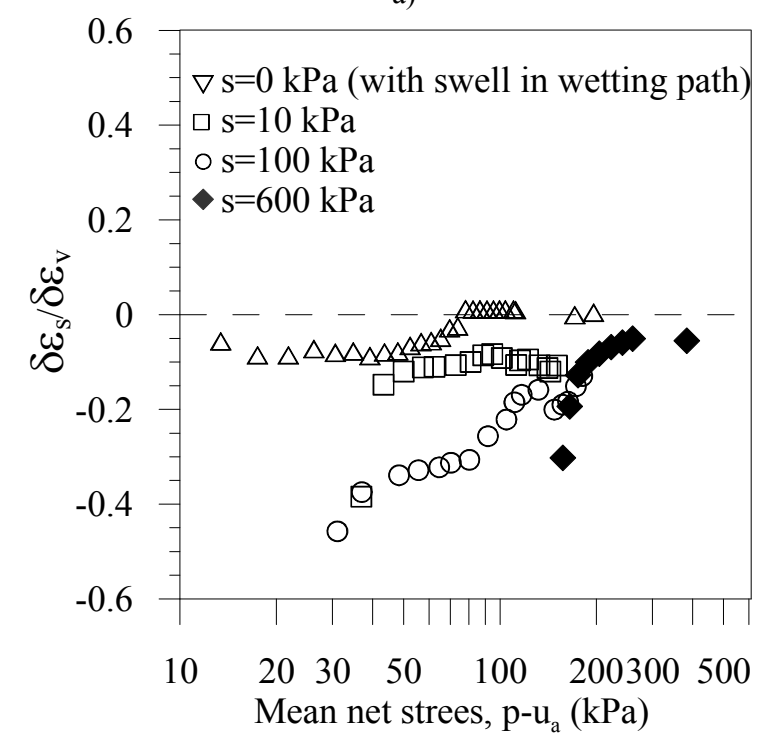

b)

Figure 4. a) Shear and volumetric strains evolutions for tests at different suctions; b) evolution of $\delta \varepsilon_{\mathrm{s}} / \delta \varepsilon_{\mathrm{v}}$ during the isotropic compression paths at different suctions.

To describe the shape of the yield surface, the following expression can be used in terms of mean net stresses [12]:

$$
\left[q-\alpha\left(p^{\prime \prime}+p_{s}\right)\right]^{2}=M^{2}\left(p^{\prime \prime}+p_{s}\right)\left(p_{m}-p ”\right)
$$

where $\alpha$ and $M$ indicate the slope of the yield surface and the critical state line, respectively, and $p_{s}$ and $p_{m}$ indicate the minimum and maximum values of the mean net stress $p$ ". Parameters $p_{s}$ and $p_{m}$ increase with suction and the angle $\alpha$ decreases with plastic strains.

As indicated above, for $s=100 \mathrm{kPa}$ the soil exhibits a behaviour with near-zero values of shear strains in the path with stress ratio of $\eta=0.38$. This suggests that the path approaches the angle of inclination $\eta=\alpha$ of the yield surface $[9,10]$. Figure 6 shows the location of the yield points obtained in the compression tests performed at $s=100 \mathrm{kPa}$. In the same figure, an estimation of a yield 
surface is included. Values of 30 and $114 \mathrm{kPa}$ can be estimated for parameters $p_{s}$ and $p_{m}$, respectively, which are also plotted in the figure.

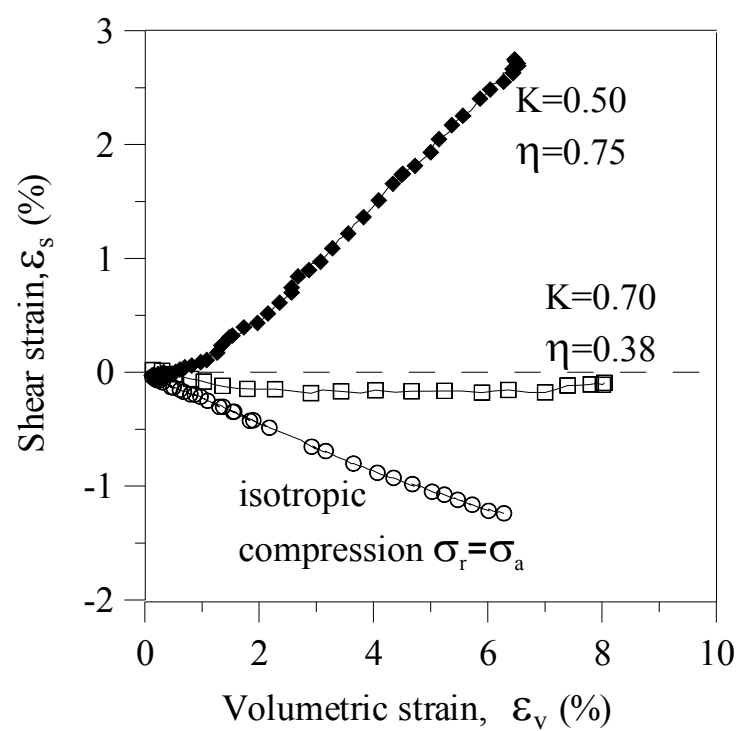

a)

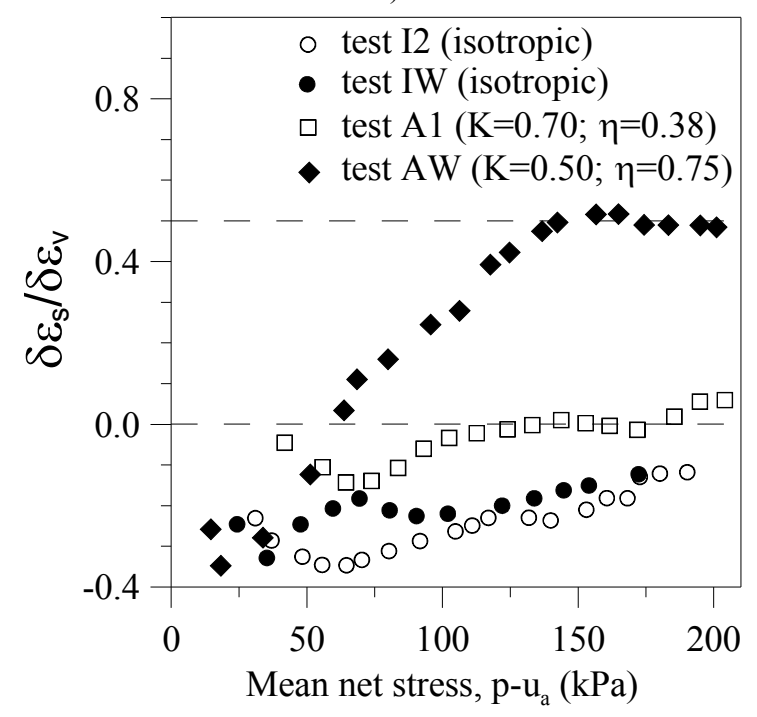

b)

Figure 5. a) Evolution of shear and volumetric strains for tests at different stress ratios $(\eta)$ and $s=100 \mathrm{kPa}$. b) Evolution of $\delta \varepsilon_{s} / \delta \varepsilon_{v}$ during the compression paths at $s=100 \mathrm{kPa}$ and for different stress ratios $(\eta)$.

\subsection{Behaviour of soil after saturation}

Volumetric strains were observed during the saturation process under low confining stress. In test SI at a mean net stress of $9 \mathrm{kPa}$ a swelling strain of $-0.5 \%$ was measured on soaking. In the remaining tests, where the saturation process was made under a higher confinement stress $(21 \mathrm{kPa})$, collapse volumetric strains ranged between $1.6 \%$ and $4.9 \%$.

Figure $7 \mathrm{a}$ presents the yield points in the space $p^{\prime}-q$ for different paths under saturated conditions. These data are associated with a yield surface $f_{0}$, which corresponds to the initial state after saturation. The shape of yield surface is consistent with that expected for a soil with isotropic mechanical behaviour. In the tests in which the sample collapse during saturation, values of effective yield mean stress $p{ }_{0}$ ranging between $29 \mathrm{kPa}$ and $31 \mathrm{kPa}$ were obtained. On the other hand a lower value $p^{\prime}{ }_{0}=11 \mathrm{kPa}$ was obtained in test SI 1 that underwent swelling during saturation. This suggests that collapse strains induced an increase in $p_{0}^{\prime}$ associated with hardening [9].

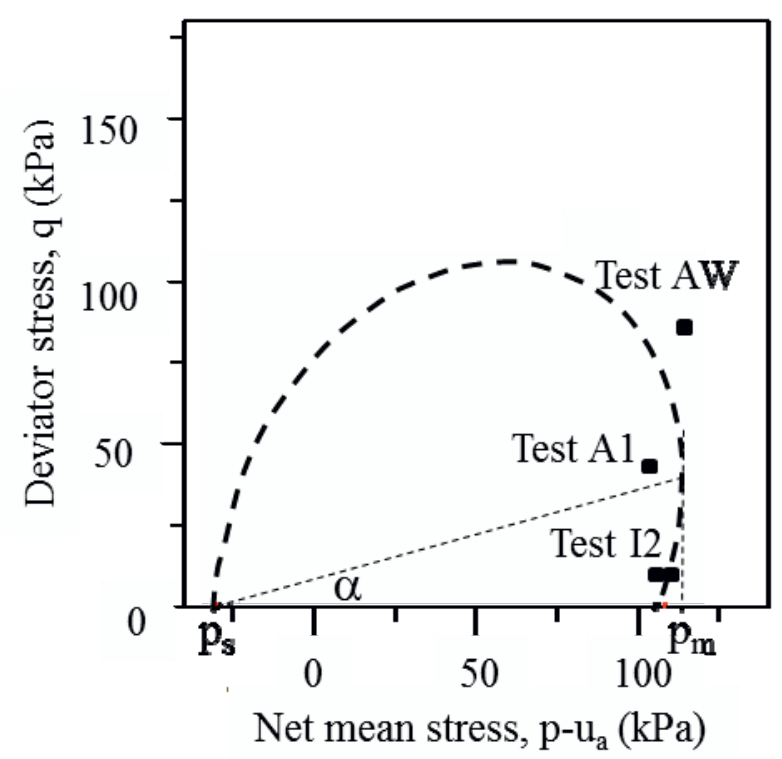

Figure 6. Yield points and estimated yield surface for different compression paths at a controlled suction of $100 \mathrm{kPa}$.

The modified Cam-Clay model has been used to plot the yield surfaces using a value of $M=1.2$ (drained friction angle of $30^{\circ}$ ), which corresponds to the value obtained in conventional drained triaxial tests performed on saturated samples [6]. The good agreement suggests that, after collapse, soil behaves like an isotropic material. The anisotropy that exhibits the soil at the end of the compaction (as suggested by the mechanical behaviour observed in unsaturated samples) appears to be erased after collapse by saturation.

Figure $7 \mathrm{~b}$ provides information on the evolution of $\delta \varepsilon_{s} \delta \varepsilon_{v}$ with the increase of mean effective stress $p^{\prime}$ from the samples that collapse during saturation. All of the $p^{\prime}-$ $\delta \varepsilon_{s} / \delta \varepsilon_{v}$ curves tend to stabilise at a certain value that depends on the value of the applied stress ratio $\eta$. The values of $\delta \varepsilon_{s} / \delta \varepsilon_{v}$ are different from those obtained in the paths at $s=100 \mathrm{kPa}$ (see Figure 5b).

In the isotropic compression test, the value of $\delta \varepsilon_{s} / \delta \varepsilon_{v}$ is approximately 0.1 at yielding at $p^{\prime} \approx 30 \mathrm{kPa}$, but it stabilises at values close to 0 when it reaches $p^{\prime} \approx 50 \mathrm{kPa}$. In the anisotropic compression test with $\eta=0.36$, the value of $\delta \varepsilon_{s} / \delta \varepsilon_{v} \approx 0$. 59, which was measured at yield point $\left(p^{\prime}=\right.$ $26 \mathrm{kPa}$ ), decreases up to about 0.25 at $p^{\prime} \approx 40 \mathrm{kPa}$. The estimated value of $\delta \varepsilon_{s} / \delta \varepsilon_{v}$ using the Cam-Clay model for $\eta=0.36$ is 0.55 . This value is consistent with the one obtained experimentally at yield state. However, its decrease and subsequent stabilisation towards 0.25 cannot be explained by this model. The same occurs for the path at $\eta=0.86$ where a value of $\delta \varepsilon_{s} / \delta \varepsilon_{v}=2.46$ is predicted by the Cam-Clay model and smaller values around 0.8 are obtained in the tests. 


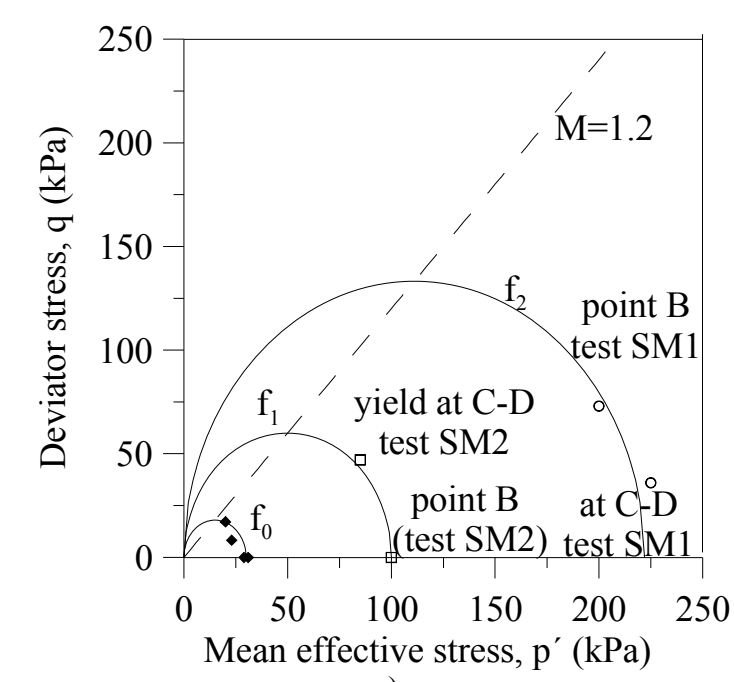

a)

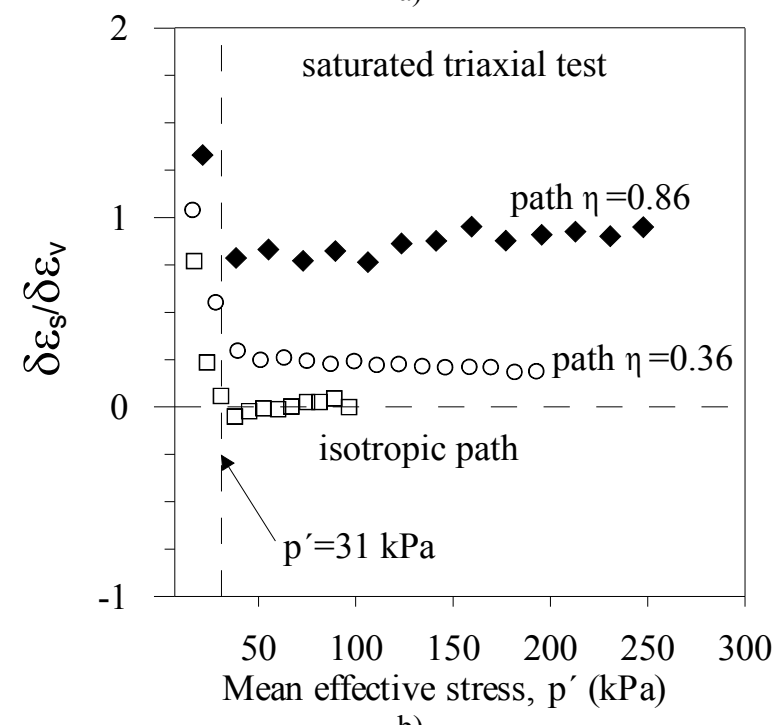

b)

Figure 7. a) Yield points and estimated yield surfaces obtained from saturated samples. b) Evolution of $\delta \varepsilon_{s} / \delta \varepsilon_{v}$ with effective mean stress $\left(p^{\prime}\right)$.

\section{CONCLUSIONS}

Performance of suction-controlled triaxial tests on a silty clay has shed light on the effects of the anisotropy set up by the static compaction process. It has been found that the behaviour of the compacted material is well represented by an anisotropic yield surface with an inclination linked to the oedometer conditions applied duding compaction. Significant shear strains develop during the isotropic compression of compacted specimens indicating unambiguously the presence of anisotropy.

It has also been observed that the inclination of the yield surface evolves during the application of radial stress paths and the development of plastic volumetric strains. The changes in the direction of plastic strain increment vectors observed experimentally upon wetting contribute to a better definition of the anisotropy evolution.

It is also interesting to note that the anisotropy that exhibits the soil at the end of the compaction appears to fade after collapse by saturation.

\section{References}

1. Y. Cui, P. Delage, Géotechnique 46 (2), 291-311 (1996)

2. S.J. Wheeler, V. Sivakumar, Géotechnique 50 (4), 369-376 (2000)

3. G. Della Vechia, C. Jommi, E. Romero, Int. J. Numer. Anal. Meth. Geomech. 37, 503-535 (2013)

4. A.M. Hansan, S.J. Wheeler, Proceedings of the Sixth International Conference on Unsaturated Soils, UNSAT 2014. Sydney, Australia (2014)

5. E. Romero and C. Jommi. Water Resour Res; 44,W12412, 1-16 (2008)

6. C. Buenfil, Caracterización experimental del comportamiento hidromecánico de una arcilla compactada (in Spanish), Tesis de Doctorado, Universidad Politécnica de Cataluña, Barcelona, España, (2007)

7. C. Buenfil, E. Romero, A. Lloret, A. Gens, The International Conference from Experimental Evidence Towards Numerical Modeling of Unsaturated Soils. Unsaturated Soils: Experimental Studies, Weimar, Germany, Springer, ISBN: 3-54021121-7, 331-342 (2004)

8. C. Rampino, C. Mancuso, F. Vinale, Can. Geot. J. 36, 1-12 (1999)

9. E.E. Alonso, A. Gens, A. Josa, Géotechnique 40 (3), 405-430 (1990)

10. S.J. Wheeler, A. Naatanen, M. Karstunen M. Lojander, Can. Geot. J. 40, 403-418 (2003)

11. M. A. Al-Sharrad, Evolving anisotropy in unsaturated soils: experimental investigation and constitutive modelling. $\mathrm{PhD}$ thesis, University of Glasgow, UK. (2013) 